Check for updates

Cite this: RSC Adv., 2018, 8, 24883

\title{
Hollow silica capsules for amphiphilic transport and sustained delivery of antibiotic and anticancer drugs
}

\author{
Isabel Gessner, $\dagger^{a}$ Eva Krakor, $\dagger^{a}$ Anna Jurewicz, ${ }^{a}$ Veronika Wulff, ${ }^{b}$ Lasse Kling, (D) ${ }^{c}$

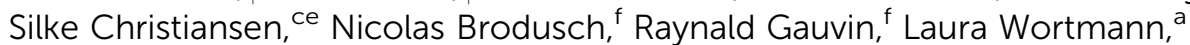 \\ Martina Wolke, ${ }^{d}$ Georg Plum, ${ }^{d}$ Astrid Schauss, ${ }^{b}$ John Krautwurst, ${ }^{a}$ \\ Uwe Ruschewitz, (D) ${ }^{\text {a }}$ Shaista llyas ${ }^{\mathrm{a}}$ and Sanjay Mathur (D) *a
}

Hollow mesoporous silica capsules (HMSC) are potential drug transport vehicles due to their biocompatibility, high loading capacity and sufficient stability in biological milieu. Herein, we report the synthesis of ellipsoid-shaped HMSC (aspect ratio $~ 2$ ) performed using hematite particles as solid templates that were coated with a conformal silica shell through cross-condensation reactions. For obtaining hollow silica capsules, the iron oxide core was removed by acidic leaching. Gas sorption studies on HMSC revealed mesoscopic pores (main pore width $\sim 38 \AA$ ) and a high surface area of $308.8 \mathrm{~m}^{2} \mathrm{~g}^{-1}$. Cell uptake of dye-labeled HMSC was confirmed by incubating them with human cervical cancer (HeLa) cells and analyzing the internalization through confocal microscopy. The amphiphilic nature of HMSC for drug delivery applications was tested by loading antibiotic (ciprofloxacin) and anticancer (curcumin) compounds as model drugs for hydrophilic and hydrophobic therapeutics, respectively. The versatility of HMSC in transporting hydrophilic as well as hydrophobic drugs and a $\mathrm{pH}$ dependent drug release over several days under physiological conditions was demonstrated in both cases by UV-vis spectroscopy. Ciprofloxacin-loaded HMSC were additionally evaluated towards Gram negative ( $E$. coli) bacteria and demonstrated their efficacy even at low concentrations $\left(10 \mu \mathrm{gl}^{-1}\right)$ in inhibiting complete bacterial growth over 18 hours.

\author{
Received 30th April 2018 \\ Accepted 21st June 2018 \\ DOI: $10.1039 / \mathrm{c} 8 \mathrm{ra03716g}$ \\ rsc.li/rsc-advances
}

\section{Introduction}

Mesoporous silica nanoparticles are promising vehicles for sustained drug release applications due to intrinsic advantages such as tunable capacities for confinement of pharmaceuticals, biocompatibility, uniform sizes and protocols available to covalently attach various biomolecules through the surfacerooted silanol groups. ${ }^{1-3}$ In comparison to silica based molecular sieves (MCM-41, MCM-48 and SBA-15), hollow mesoporous

\footnotetext{
${ }^{a}$ Institute of Inorganic Chemistry, University of Cologne, Greinstr. 6, 50939 Cologne, Germany. E-mail: sanjay.mathur@uni-koeln.de

${ }^{b}$ Cluster of Excellence - Cellular Stress Responses in Aging-Associated Diseases (CECAD), Imaging Facility, University of Cologne, Joseph-Stelzmann-Str. 26, 50931 Cologne, Germany

${ }^{\prime}$ Max Planck Institute for the Science of Light, Günther-Scharowsky-Straße 1 Bau 26, 91058 Erlangen, Germany

${ }^{d}$ Institute for Medical Microbiology, Immunology and Hygiene, Goldenfelsstraße 19-21, 50935, Cologne, Germany

${ }^{e}$ Helmholtz Institut Berlin für Materialien und Energie (HZB), Hahn-Meitnerplatz 1, 14109 Berlin, Germany

${ }^{f}$ Department of Mining and Materials Engineering, McGill University, Montreal, Quebec, Canada

$\dagger$ Equal contribution.
}

silica capsules (HMSC) offer a porous shell and internal voids available for loading drug molecules. ${ }^{\mathbf{1 , 4 5}}$ Hollow nanoparticles are commonly prepared via template-assisted routes using either soft (e.g., emulsions, polymers) or hard (e.g., metals and metal oxides) sacrificial templates. ${ }^{6,7}$ Soft templating techniques often result in non-uniform size and morphology and lack of control over shell thickness due to the dynamics of selfassembly and disintegration processes. These parameters can be precisely controlled when employing easy to remove hard templates of defined sizes. ${ }^{8}$ So far, hollow spherical silica capsules have been used as containers for a variety of drugs such as ibuprofen, doxorubicin and aspirin. ${ }^{9-11}$ Recently, Huang et al. have demonstrated that silica particles with a higher aspect ratio are preferentially taken up by cells compared to spherical silica particles of similar size due to an increased contact area between the longitudinal side of the particles and the cell membrane. ${ }^{12}$ Chen et al. have shown that elongated HMSC could be effectively used for the transport and release of therapeutics, such as doxorubicin for the treatment of breast cancer. $^{13}$

Here we present a simple and reproducible approach for ellipsoidal HMSC synthesized using a hard iron oxide template that was dissolved by acidic leaching. The versatile application 
of HMSC in sustained drug release was demonstrated by efficiently loading them with hydrophilic (ciprofloxacin) as well as hydrophobic (curcumin) drugs. Moreover, ciprofloxacin loaded hollow capsules showing strong antibacterial activity were successfully used against $E$. coli bacteria.

\section{Experimental}

\section{Chemicals}

All reagents and solvents were of analytical grade and used without further purification. Iron(III) chloride hexahydrate $\left(\mathrm{FeCl}_{3} \cdot 6 \mathrm{H}_{2} \mathrm{O}, 97 \%\right)$, tetraethyl orthosilicate (TEOS) and ciprofloxacin (98\%) were purchased from Sigma-Aldrich, while diammonium hydrogen phosphate $\left(\left(\mathrm{NH}_{4}\right)_{2} \mathrm{HPO}_{4}, 99+\%\right)$ was procured from Merck and ammonium hydroxide solution $\left(\mathrm{NH}_{4} \mathrm{OH}, 28-30 \%\right)$ from Fluka. Cell culture materials were obtained by Life Technologies except for paraformaldehyde (PFA) (Merck) and thiazolyl blue tetrazolium bromide (MTT, 98\%, Alfa Aesar).

\section{Synthesis of $\alpha-\mathrm{Fe}_{2} \mathrm{O}_{3}$ particles}

Ellipsoid-shaped $\alpha-\mathrm{Fe}_{2} \mathrm{O}_{3}$ particles were prepared using a solvothermal approach following a modified method by Lv et al. ${ }^{\mathbf{1 4}}$ In a typical synthesis, $337.8 \mathrm{mg}(1.24 \mathrm{mmol}) \mathrm{FeCl}_{3} \cdot 6 \mathrm{H}_{2} \mathrm{O}$ were dissolved in $50 \mathrm{ml}$ distilled water followed by the addition of $3.30 \mathrm{mg}(0.025 \mathrm{mmol})\left(\mathrm{NH}_{4}\right)_{2} \mathrm{HPO}_{4}$. The solution was stirred for 30 minutes, transferred into a Teflon lined steel autoclave $(V=$ $50 \mathrm{ml}$ ) which was tightly closed and heated for 6 hours at $220^{\circ} \mathrm{C}$. The obtained red-brownish particles were washed four times with distilled water (9000 rpm, 15 minutes) and dried to obtain red-brownish particles for characterization purposes.

\section{Preparation of $\mathrm{SiO}_{2} @ \mathrm{Fe}_{2} \mathrm{O}_{3}$ particles}

In order to coat iron oxide particles with silicon dioxide $\left(\mathrm{SiO}_{2}\right)$, silicic acid $\left(\mathrm{H}_{4} \mathrm{SiO}_{4}\right)$ was freshly prepared by adding $0.65 \mathrm{ml}$ TEOS to $5 \mathrm{ml}$ of hydrochloric acidic solution of $\mathrm{pH} 4$ and stirred for 12 hours at ambient temperature. ${ }^{15,16}$ To a dispersion of $36 \mathrm{mg}$ of $\alpha-\mathrm{Fe}_{2} \mathrm{O}_{3}$ particles in $52 \mathrm{ml}$ distilled $\mathrm{H}_{2} \mathrm{O}, 360 \mu \mathrm{l}$ of asprepared silicic acid were added and stirred for 30 minutes at ambient temperature. Afterwards, $360 \mu \mathrm{l}$ ammonium hydroxide $\left(\mathrm{NH}_{4} \mathrm{OH}\right)$ were added and stirred for further 3 hours. The particles were separated by centrifugation (9000 rpm, 15 minutes), washed with ethanol and dispersed in $36 \mathrm{ml}$ ethanol. Afterwards, $72 \mu \mathrm{l}$ TEOS were added to the dispersion which was then stirred for 30 minutes at ambient temperature. For activating the silicate precursor, $720 \mu \mathrm{l}$ ammonium hydroxide were added and the mixture was stirred for further 3 hours. The required $\mathrm{SiO}_{2} @ \mathrm{Fe}_{2} \mathrm{O}_{3}$ particles were precipitated by centrifugation and washed with ethanol (9000 rpm, 15 minutes) three times. The product was received as red-brownish powder after drying at ambient temperature and was used for characterization purposes.

\section{Synthesis of ellipsoid-shaped HMSC}

To remove the $\alpha-\mathrm{Fe}_{2} \mathrm{O}_{3}$ core, as-prepared $\mathrm{SiO}_{2} @ \mathrm{Fe}_{2} \mathrm{O}_{3}$ particles were dispersed in concentrated hydrochloric acid $(\mathrm{HCl})(15 \mathrm{ml})$ by ultrasonication for 30 minutes. ${ }^{\mathbf{1 6}}$ Dissolution of the iron oxide core was indicated by a color change of the supernatant from transparent to yellow. The supernatant was separated from the particles by centrifugation ( $9000 \mathrm{rpm}, 15$ minutes) and the separated free $\mathrm{Fe}^{3+}$-ions in the supernatant were detected by UV-vis spectroscopy at $292 \mathrm{~nm}$. Leaching of the particle core was continued by washing with $\mathrm{HCl}$ until iron ions could no more be detected. Obtained hollow $\mathrm{SiO}_{2}$ particles were washed with water (9000 rpm, 15 minutes) for three times to remove excess $\mathrm{HCl}$ and dried at ambient temperature to obtain a white powder, which was used for characterization purposes.

\section{Synthesis of dye-labeled HMSC}

HMSC were dye-labeled with 5-FAM alkyne via a copper catalyzed click reaction. ${ }^{17,18}$ Therefore, $10 \mathrm{mg}$ HMSC were dispersed in $4 \mathrm{ml}$ dry dimethylformamide (DMF) followed by the addition of $15 \mu \mathrm{l}$ of 11-bromoundecyltrichlorosilane. The resulting solution was stirred for 12 hours at ambient temperature, centrifuged (10000 rpm, 15 minutes) and washed with a toluene/ethanol mixture $(1: 1)$ two times. In order to achieve a terminal azide group on the particle surface, the particles were redispersed in $4 \mathrm{ml}$ of dry DMF followed by the addition of $11 \mathrm{mg}$ sodium azide and stirring for 12 hours at ambient temperature. Afterwards, the particles were centrifuged (10 $000 \mathrm{rpm}, 15$ minutes) and washed with a water/ethanol mixture $(1: 1)$ several times in order to remove unbound sodium azide. The desired particles were obtained after drying at ambient temperature. For the click reaction of 5-FAM alkyne with as-prepared azide functionalized particles, three solutions were prepared separately by dissolving $62.5 \mathrm{mg}$ copper(II) sulfate (0.25 mmol) in $250 \mu \mathrm{l} \mathrm{H}_{2} \mathrm{O}, 97.5 \mathrm{mg}(0.63 \mathrm{mmol})$ L-histidine in $250 \mu \mathrm{H}_{2} \mathrm{O}$ and $245 \mathrm{mg}(1.24 \mathrm{mmol})$ sodium ascorbate in $250 \mu \mathrm{l}$ $\mathrm{H}_{2} \mathrm{O}$. Afterwards, $20.67 \mu \mathrm{l}(0.5 \mu \mathrm{mol})$ of a $50 \mathrm{mM}$ 5-FAM alkyne solution were added to the copper(II) sulfate solution, stirred and subsequently, the L-histidine and the sodium ascorbate solution were added. Finally, $10 \mathrm{mg}$ of azide functionalized particles, dispersed in $500 \mu \mathrm{l}$ of ethanol were added to the mixture and stirred in the dark for 12 hours. Dye-functionalized particles were separated by centrifugation and washed with ethanol (10 $000 \mathrm{rpm}, 15$ minutes) three times to remove any residual dye. A yellow powder was received after drying. For cell uptake studies, a dispersion was prepared by dispersing $1 \mathrm{mg}$ of particles in $1 \mathrm{ml}$ of sterile water.

\section{Characterization}

Phase and crystallinity analysis of the prepared particles was performed by recording powder X-ray diffractograms on a STOESTADI MP X-ray diffractometer (XRD) with Mo $\mathrm{K} \alpha$ radiation $(\lambda=$ $0.7093 \AA$ ) and measured peak patterns were compared to reference JCPDS files. Size and morphology of particles was analyzed using Nova Nano SEM 430 field-emission scanning electron microscope (SEM) and ZEISS Leo912 transmission electron microscope (TEM) operated at an acceleration voltage of $120 \mathrm{kV}$. For sample preparation, particles dispersed in $\mathrm{EtOH}$ were dropped on a carbon-covered standard TEM grid (QUANTIFOIL Multi A) and dried under air. Moreover, high resolution 
secondary electron (SE) as well as bright field (BF) and highangle annular dark field (HAADF) images of HMSC were taken using a low accelerating voltage scanning transmitted electron microscope (SU9000, Hitachi). Furthermore, Fourier transform infrared spectroscopy (FTIR, Perkin Elmer) between 400 and $4000 \mathrm{~cm}^{-1}$ and UV-vis spectroscopy (LAMBDA 950 Perkin Elmer) was employed for particle surface characterization and drug release experiments. Zeta-potential and dynamic light scattering (DLS) measurements were done using a Zetasizer Nano ZS (Malvern Instruments) at a wavelength of $633 \mathrm{~nm}$. Samples were measured as dispersions in distilled water with a pH of 6.5. Sorption measurements $\left(\mathrm{N}_{2}\right.$ at $\left.77 \mathrm{~K}\right)$ were performed to determine the porosity of HMSC using an AUTOSORB-1-MP (Quantachrome). Prior to the sorption measurements, the sample was heated to $100{ }^{\circ} \mathrm{C}$ under vacuum $\left(1 \times 10^{-7} \mathrm{mbar}\right)$ for 20 hours to give solvent-free HMSC. The Brunauer-Emmett-Teller (BET) surface area was calculated based on the pressure region $P / P_{0}=$ $0.05-0.25$. In order to define the pore size distribution and volume, DFT calculations were performed using the cylindrical/ sphere pore, NLDFT ads. model with a fitting error of $0.7 \%$. Cell uptake images were acquired with a confocal laser scanning microscope (Meta 710, Zeiss) using a $63 \times$ oil objective with a numerical aperture of 1.4 .

\section{Drug loading and release of HMSC}

HMSC were loaded with ciprofloxacin and curcumin using a diffusion-based approach. For ciprofloxacin loaded HMSC, $5 \mathrm{ml}$ of a $50 \mathrm{mM}$ stock solution in $0.01 \mathrm{~N} \mathrm{HCl}(\mathrm{pH} 1)$ was prepared due to low solubility of ciprofloxacin at neutral $\mathrm{pH}$. For curcumin loaded HMSC, $5 \mathrm{ml}$ of a $8.2 \mathrm{mM}$ solution was prepared in ethanol. To each solution, $5 \mathrm{mg}$ HMSC were added and the resulting dispersions were stirred for 12 hours at ambient temperature. A photograph of loaded and unloaded HMSC in dispersion as well as in powder form after drying under ambient conditions is shown in Fig. 1.

As-obtained loaded particles were washed with ethanol (ciprofloxacin) and water (curcumin) for four times $(11000 \mathrm{rpm}$, 5 minutes) to prevent an early release of the drug. To quantify the amount of drug in the supernatant, a calibration curve was recorded under the same conditions. In order to start the drug release, the supernatant was removed by centrifugation (11 $000 \mathrm{rpm}, 5$ minutes) and replaced with $5 \mathrm{ml}$ of release medium. The sample was stirred in a water bath with a constant temperature of $37^{\circ} \mathrm{C}$ for the period of drug release. The amount of released drug was determined after several time points, whereby the supernatant was separated via centrifugation (11 $000 \mathrm{rpm}, 5$ minutes) and absorption data was measured using UV-vis spectroscopy. The same amount of removed medium was replaced with fresh one to obtain a cumulative release of the drug. Three independent release measurements were performed for both drugs.

\section{Cell viability evaluation of HMSC by MTT assay}

Cell viability of HEK293 cells (obtained through Leibniz Institute DSMZ - German Collection of Microorganisms and Cell Cultures, ACC 305) was measured after incubation with HMSC to evaluate the cytotoxic potential of the carrier material. The employed procedure was similar to previously reported methods. ${ }^{15}$ In short, HEK293 cells were grown using Dulbecco's Modified Eagle Medium (DMEM) containing 10\% fetal calf

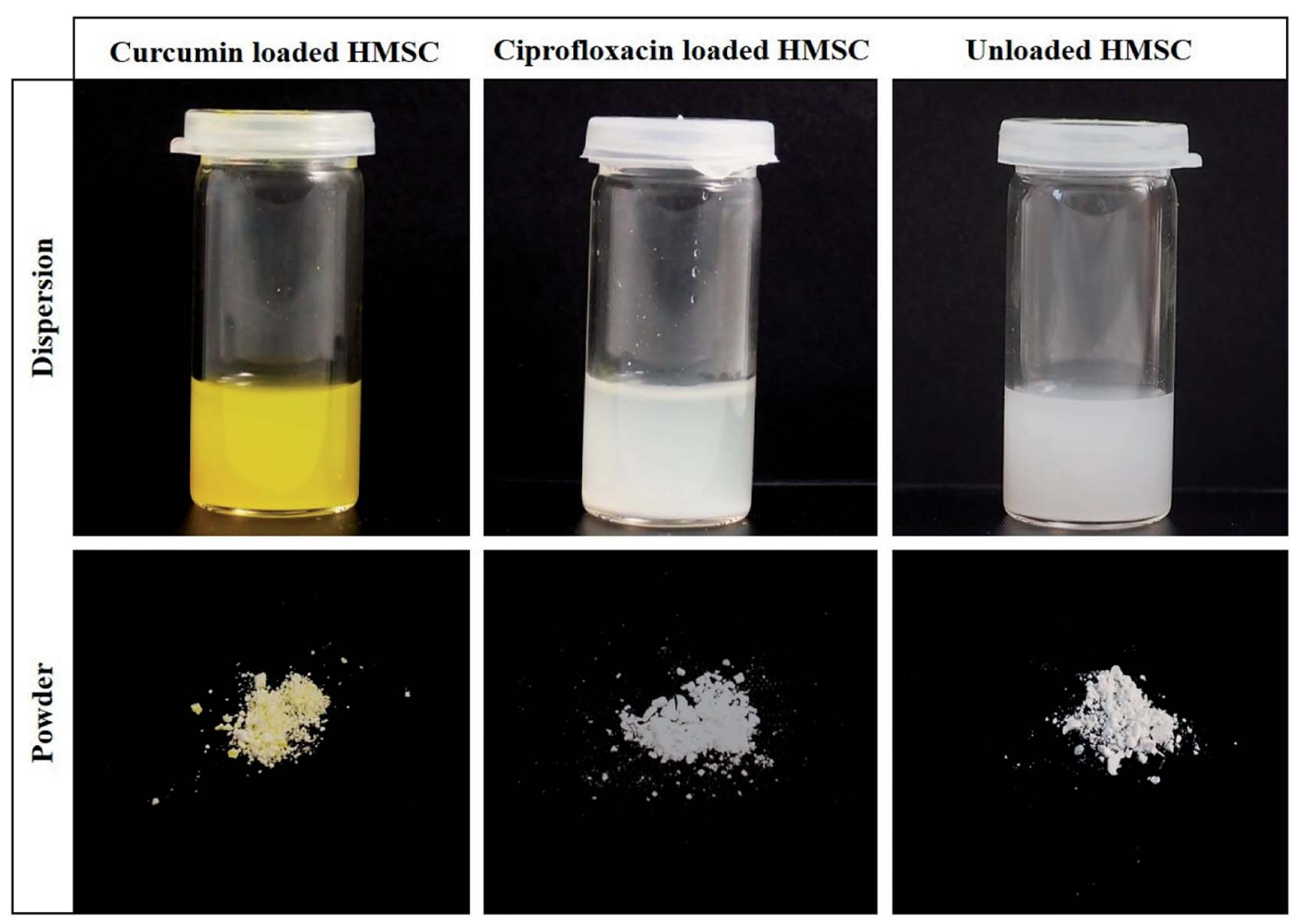

Fig. 1 Photographs of dispersions and corresponding powders of curcumin loaded HMSC, ciprofloxacin loaded HMSC and unloaded HMSC. 
serum and $1 \%$ penicillin/streptavidin at $37{ }^{\circ} \mathrm{C}$ and $5 \% \mathrm{CO}_{2}$. 8000 cells were seeded per well into a 96 well plate and incubated for 24 hours. A stock solution of $\operatorname{HMSC}\left(1 \mathrm{mg} \mathrm{ml}^{-1}\right)$ was prepared using DMEM and treated with UV light for one hour to avoid bacteria contaminations. Then, $200 \mu \mathrm{l}$ of a serial dilution $\left(5 \mu \mathrm{g} \mathrm{ml}^{-1}, 10 \mu \mathrm{g} \mathrm{ml}^{-1}, 20 \mu \mathrm{g} \mathrm{ml}^{-1}, 50 \mu \mathrm{g} \mathrm{ml}^{-1}\right.$ and $100 \mu \mathrm{g} \mathrm{ml}^{-1}$ ) was added to each well. Each concentration was measured six times. After 48 hours incubation time at $37{ }^{\circ} \mathrm{C}$ and $5 \% \mathrm{CO}_{2}$, the supernatant was carefully removed and $30 \mu \mathrm{l}$ of sterile MTT solution (5 mg ml $\mathrm{ml}^{-1}$ in phosphate buffered saline (PBS)) was added. The forming formazan crystals were dissolved after 4 hours incubation time by adding $150 \mu$ dimethyl sulfoxide (DMSO) to each well and the absorbance was measured at $490 \mathrm{~nm}$ with $630 \mathrm{~nm}$ as reference using an ELISA plate reader. As a reference, the absorbance of the HMSC at the same wavelengths was measured.

\section{Cellular uptake of HMSC-FAM}

Uptake of FAM functionalized HMSC was tested using HeLa cells (European Collection of Authenticated Cell Cultures 85060701). HeLa cells were maintained at $37{ }^{\circ} \mathrm{C}$ in a $5 \% \mathrm{CO}_{2}$ atmosphere in DMEM supplemented with 10\% fetal bovine serum, MEM nonessential amino acids, $2 \mathrm{mM}$ L-glutamine, $1 \mathrm{mM}$ sodium pyruvate and 1\% penicillin/streptomycin. Therefore, $45000 \mathrm{HeLa}$ cells were seeded on a $12 \mathrm{~mm}$ round sterile glass coverslip and were incubated in complete media for 12 hours. $25 \mu \mathrm{g}$ of HMSCFAM were added as dispersion in complete medium to each well and cells were incubated for various times between 15 minutes and 24 hours. Afterwards, cells were washed with PBS and stained using Cell Mask Plasma Membrane Stain $1: 1000$ in complete media for 5-10 minutes. After an additional washing step with PBS, cells were fixed with pre-warmed 4\% PFA in PBS for 15 minutes at $37{ }^{\circ} \mathrm{C}$, washed three times with PBS and quenched with $50 \mathrm{mM}$ ammonium chloride for 15 minutes. Then, coverslips were washed with PBS and briefly washed in water and mounted with a drop of ProLong Gold mounting medium onto a microscope slide. Samples were stored at $8{ }^{\circ} \mathrm{C}$ in the dark until their use in confocal microscopy studies.

\section{Antibacterial evaluation of ciprofloxacin loaded HMSC}

The antibacterial activity of HMSC loaded with ciprofloxacin was determined by an antibacterial kinetic growth assay commonly used for antibiotics. ${ }^{19}$ Escherichia coli (ATCC 25922) cultures were obtained from Institute for Microbiology, Immunology and Hygiene, Uniklinik Cologne and were used as model bacteria for this study. The antibacterial kinetic growth of loaded HMSC was measured by a microplate reader (TECAN, infinite M1000). First, bacteria cultures were incubated in $10 \mathrm{ml}$ of Müller-Hinton (M-H) broth in a shaking incubator at $37{ }^{\circ} \mathrm{C}$ (innova4200, NEW BRUNSWICK SCIENTIFIC). As soon as the optical density at $600 \mathrm{~nm}\left(\mathrm{OD}_{600}\right)$ of the culture suspensions reached 0.5 , dilutions of $1: 10$ with twofold $\mathrm{M}-\mathrm{H}$ broth were produced to prepare the starting concentrations. Different concentrations of ciprofloxacin loaded HMSC (CIP-HMSC) were tested $\left(1.07 \mu \mathrm{g} \mathrm{ml}{ }^{-1}, 1.86 \mu \mathrm{g}\right.$ $\mathrm{ml}^{-1}, 3.20 \mu \mathrm{g} \mathrm{ml}^{-1}, 5.71 \mu \mathrm{g} \mathrm{ml}^{-1}$ and $10.00 \mu \mathrm{g} \mathrm{ml}^{-1}$ ) using 96 well plates inoculated with serial dilutions of HMSC and bacteria suspension with a volume of $100 \mu \mathrm{l}$ each. For comparison, a negative control with no addition of drug or particles was measured as well as a positive control using $0.2 \mu \mathrm{g} \mathrm{ml} \mathrm{m}^{-1}$ ciprofloxacin. Moreover, a control with unloaded HMSC was applied $\left(10.00 \mu \mathrm{g} \mathrm{ml}^{-1}\right)$ to exclude any antibacterial effects by the particles itself. During a time period of 18 hours at $37^{\circ} \mathrm{C}, \mathrm{OD}_{600}$ was measured every 30 minutes by a TECAN microplate reader. All measurements were done as triplicates.

\section{Results and discussion}

Hematite $\left(\alpha-\mathrm{Fe}_{2} \mathrm{O}_{3}\right)$ particles synthesized following a published procedure $^{\mathbf{1 4 , 1 5}}$ were used as hard templates and homogenously coated with a sol containing $\mathrm{H}_{4} \mathrm{SiO}_{4}$ and $\mathrm{Si}(\mathrm{OEt})_{4}$. Subsequently, the iron oxide core was dissolved out by treating the $\mathrm{SiO}_{2}$ @$\mathrm{Fe}_{2} \mathrm{O}_{3}$ core-shell particles with concentrated hydrochloric acid resulting in ellipsoidal silica capsules as schematically represented in Fig. 2.

The morphology of the hematite templates was confirmed by scanning electron microscopy that demonstrated the formation of ellipsoid-shaped homogeneous particles (Fig. 2B). The selective formation of elongated particles is attributed to the preferred adsorption of phosphate anions to specific crystal facets that exerts a shape-directing influence. While (001) facets are doubly surface coordinated with hydroxyl functions, other facets such as (110), (100) and (012) are only singly coordinated. Therefore, the adsorption affinity for phosphate anions is lower for (001) facets, leading to an anisotropic growth in the [001] direction, which was already discussed in more detail in the literature. ${ }^{\mathbf{1 4 , 2 0}}$ In fact, the morphology of prepared particles can be easily controlled by adjusting the concentration of $\mathrm{H}_{2} \mathrm{PO}_{4}{ }^{-}$anions. For instance, spherical particles are obtained if no $\mathrm{H}_{2} \mathrm{PO}_{4}{ }^{-}$ions are employed during the synthesis, whereas ellipsoid-shaped particles are formed at $\mathrm{H}_{2} \mathrm{PO}_{4}{ }^{-}$concentrations ranging from $0.25 \mathrm{mM}$ to $1 \mathrm{mM}$. At higher $\mathrm{H}_{2} \mathrm{PO}_{4}{ }^{-}$concentrations of $4 \mathrm{mM}$, nanodisks and nanorings are preferentially formed. ${ }^{14}$

The average dimensions of ellipsoid-shaped iron oxide particles prepared in this study were determined by analyzing 200 particles in SEM images that revealed the axial and radial dimension to be ca. $365 \pm 32 \mathrm{~nm}$ and $158 \pm 16 \mathrm{~nm}$, respectively so that the aspect ratio was around 2. For forming a conformal silica shell, silicic acid was condensed on the surface of hematite particles by ammonia catalyzed hydrolysis and condensation followed by a shell-growth via an ammonia catalyzed activation and condensation of $\mathrm{Si}(\mathrm{OEt})_{4}$. Electron micrographs confirmed the formation of a uniform shell around the hematite core with an average shell thickness of $57 \mathrm{~nm} \pm 7 \mathrm{~nm}$ (Fig. 2C). After chemical etching of the iron oxide core, hollow capsules with a mean particle length of 460 $\pm 49 \mathrm{~nm}$ and width of $242 \pm 17 \mathrm{~nm}$ were obtained. The hollow nature of ellipsoid-shaped particles after the etching process was verified by TEM analyses (Fig. 2D). Moreover, the high-resolution SEM images corroborated the shape and dimensions of the particles observed in TEM measurements (Fig. 2D and F). The secondary electron image in Fig. 2E additionally showed the surface roughness of the $\mathrm{SiO}_{2}$ shell of HMSC particles. X-ray diffraction measurements (Fig. 3A) confirmed the formation of crystalline and phase pure hematite particles. 

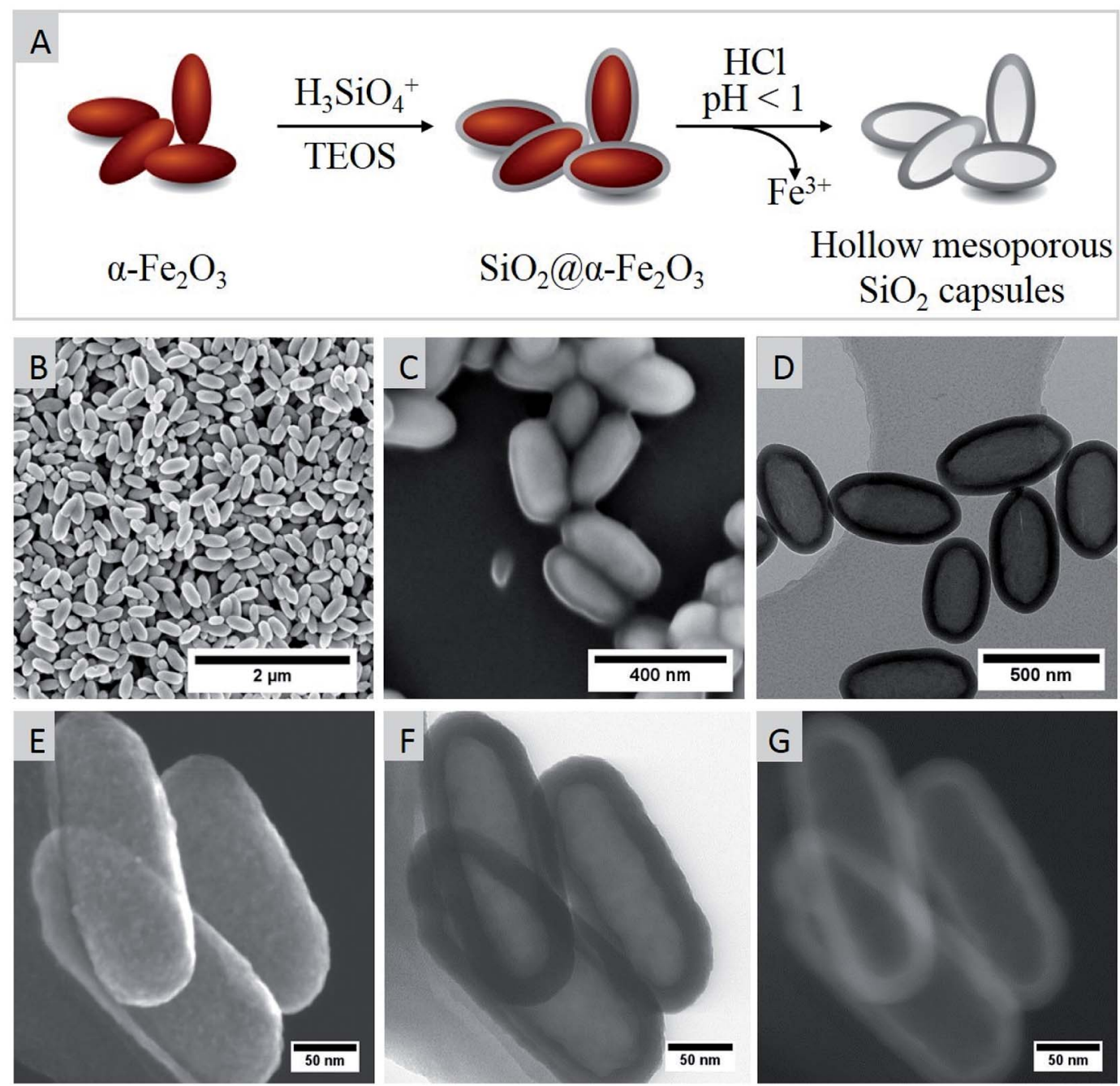

Fig. 2 Reaction scheme for the synthesis of ellipsoid-shaped HMSC starting from ellipsoid-shaped $\alpha$-Fe ${ }_{2} \mathrm{O}_{3}$ particles. The silica coating was performed using a modified Stöber-process. To obtain a hollow structure, the $\alpha-\mathrm{Fe}_{2} \mathrm{O}_{3}$ core was etched with hydrochloric acid (A). SEM images of $\alpha-\mathrm{Fe}_{2} \mathrm{O}_{3}$ templates (B), $\mathrm{SiO}_{2} @ \mathrm{Fe}_{2} \mathrm{O}_{3}$ (C) and TEM image of HMSC (D). (E-G) Additional high-resolution SEM data: (E) secondary electron image (SE), (F) scanning transmission electron microscope image (STEM) and (G) high-angle annular dark field (HAADF) images of HMSC.

The diffraction peaks observed in the XRD pattern are in good agreement with the reference pattern of rhombohedral hematite (JCPDS file no. 33-0064), with the space-group $R \overline{3} c(a=$ 5.03560 (10) $\AA, c=13.4789$ (7) $\AA^{14}{ }^{14}$
The IR spectra of as-prepared $\alpha-\mathrm{Fe}_{2} \mathrm{O}_{3}, \mathrm{SiO}_{2} @ \mathrm{Fe}_{2} \mathrm{O}_{3}$ and HMSC (Fig. 3B) showed the characteristic stretching frequencies for Fe-O-Fe units at $442 \mathrm{~cm}^{-1}$ and $526 \mathrm{~cm}^{-1}$ for $\alpha-\mathrm{Fe}_{2} \mathrm{O}_{3}$ as well as for $\mathrm{SiO}_{2} @ \mathrm{Fe}_{2} \mathrm{O}_{3}$ samples. Additionally, in both samples
A

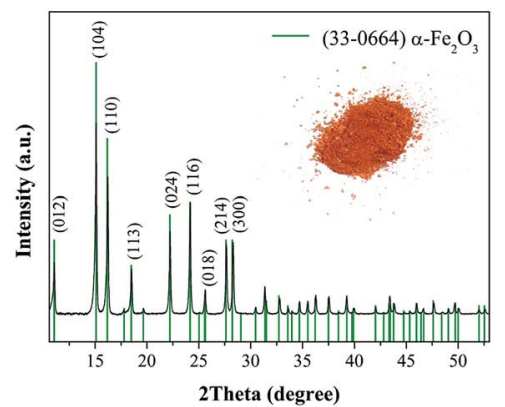

B

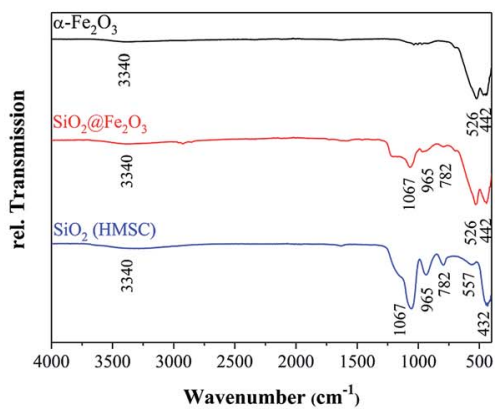

Fig. 3 (A) XRD of $\alpha-\mathrm{Fe}_{2} \mathrm{O}_{3}$ particles (black) with JCPDS file no. 33-0064 as reference (green). Inset shows a photograph of prepared hematite powder. (B) IR spectra of $\alpha-\mathrm{Fe}_{2} \mathrm{O}_{3}$ templates (black), $\mathrm{SiO}_{2} \mathrm{aFe}_{2} \mathrm{O}_{3}$ core-shell structures (red) and HMSC (blue). 
A

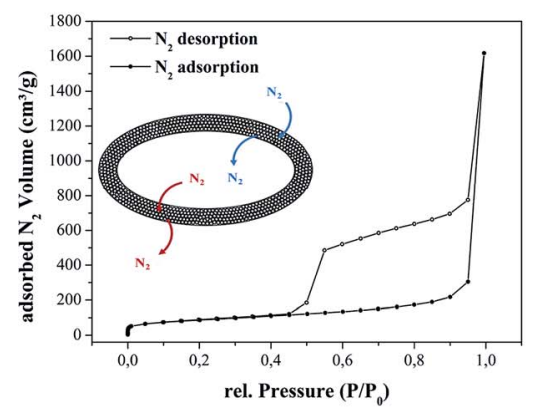

B

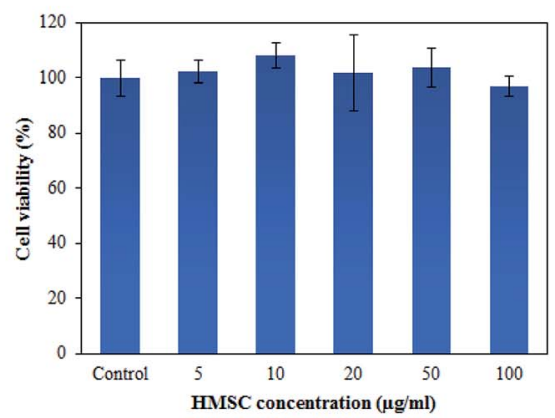

Fig. 4 (A) $\mathrm{N}_{2}$ sorption isotherm of activated HMSC at 77 K. (B) Cell viability evaluation by MTT assay: HEK293 cells after 24 hours treatment with different concentrations of HMSC.

a very broad band with low intensity was observed around $3340 \mathrm{~cm}^{-1}$, indicating the presence of surface-bound water molecules and silanol groups. This is additionally supported by the deformation vibration bands of water observed around $1625 \mathrm{~cm}^{-1} .{ }^{21}$ The successful formation of a $\mathrm{SiO}_{2}$ overlayer on $\alpha$ $\mathrm{Fe}_{2} \mathrm{O}_{3}$ particles was further indicated by the presence of $\mathrm{Si}-\mathrm{O}-\mathrm{Si}$ bands at $1067 \mathrm{~cm}^{-1}$ and $437 \mathrm{~cm}^{-1}$ as well as $\mathrm{Si}-\mathrm{OH}$ oscillation bands at $965 \mathrm{~cm}^{-1}$ and $782 \mathrm{~cm}^{-1} \cdot{ }^{22,23}$ After the etching process, the $\mathrm{Fe}-\mathrm{O}-\mathrm{Fe}$ vibration at $526 \mathrm{~cm}^{-1}$ disappeared which suggested the successful removal of the iron oxide core. The complete leaching of $\mathrm{Fe}^{3+}$ ions was confirmed by UV-vis spectroscopy and was verified by EDX analyses that did not show any residual iron in the HMSC samples.

Zeta potential measurements revealed a negatively charged surface for all three types of particles. In direct comparison, the zeta potential decreased from $-10.4 \mathrm{mV}$ for $\alpha-\mathrm{Fe}_{2} \mathrm{O}_{3}$ particles to more negative values of $-33.4 \mathrm{mV}$. This trend is in good accordance to previously published results and can be explained by the deprotonation of hydroxyl groups which are present in high number on the surface after silica coating. ${ }^{24}$ The strong negative potential of silica coated particles was supported by the high colloidal stability due to the electrostatic repulsion between the particles. The DLS measurements indicated an expected increase in hydrodynamic diameter from 308 $\pm 5 \mathrm{~nm}$ to $490 \pm 20 \mathrm{~nm}$ after coating of the particles. Since DLS measurements are based on an equation for spherical particles, the ellipsoid-shaped nature of these particles was not taken into account. In contrast to spherical particles, where light is isotropically scattered, elongated structures showed a dimension dependent scattering. Based on the random orientation of these particles in solution, differences in horizontal and longitudinal axes cannot be resolved but instead a mean value is measured.

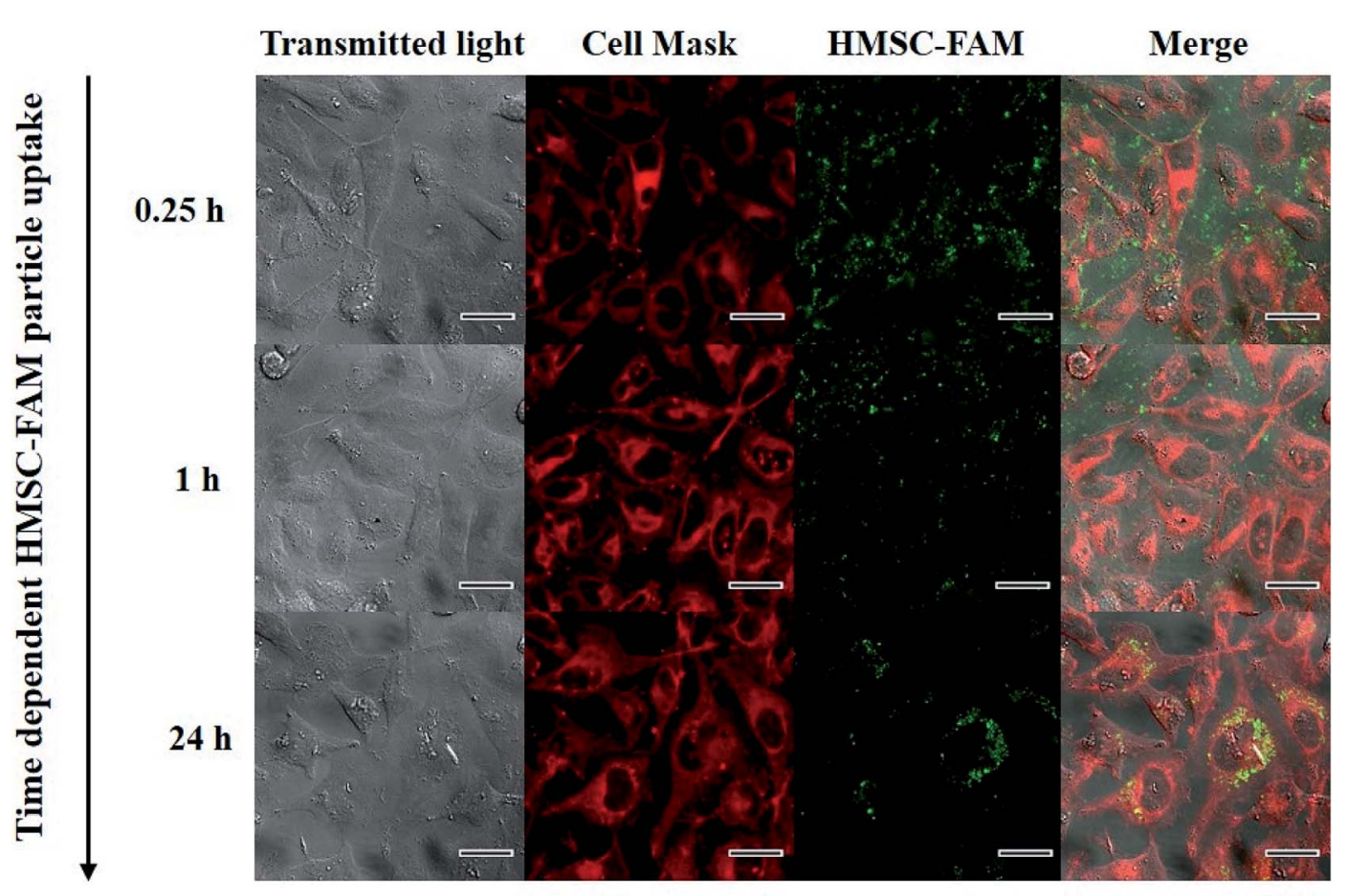

Fig. 5 Time dependent cell uptake study of HMSC-FAM in HeLa cells. Cells were stained with Cell Mask before fixation and imaging. Scale bar in all images refers to $25 \mu \mathrm{m}$. 
Therefore, the obtained diameter values were taken as approximations that show deviations from the dimensions observed in TEM analyses.

The $\mathrm{N}_{2}$ sorption studies of HMSC revealed a type IV isotherm behaviour characteristic for mesoporous materials (Fig. 4A). ${ }^{25,26}$ The sharp increase at low relative pressures is caused by monolayer-multilayer adsorption which is subsequently followed by capillary condensation at higher relative pressures. The observed hysteresis loop is typical for capillary condensation in mesopores.

The surface area of the HMSC determined by BET measurements $\left(308.8 \mathrm{~m}^{2} \mathrm{~g}^{-1}\right)$ is in good agreement with previously reported data for hollow $\mathrm{SiO}_{2}$ particles. ${ }^{16}$ Additionally, we performed NLDFT calculations to determine the pore size distribution and total pore volume of the HMSC. Mesopores with a main width of $\sim 38 \AA$ and a total pore volume of $0.38 \mathrm{~cm}^{3} \mathrm{~g}^{-1}$ were calculated. These results demonstrate the porous texture and high surface area of as-prepared HMSC and their corresponding great potential for drug delivery applications.

An MTT assay performed to assess cell viability demonstrated (Fig. 4B) that no reduction in cell viability occurred even at high concentrations of $100 \mu \mathrm{g} \mathrm{ml}^{-1}$ of HMSC with HEK293 cells after an incubation period of 24 hours. In order to track the particles inside the cancer cells, the surface functionalization of HMSC with dye molecules (5-FAM) was performed. For this purpose, time-dependent uptake studies were undertaken by incubating (1-24 hours) dye-tagged HMSC with the HeLa cells that were subsequently stained with a cell membrane dye (Cell Mask), fixed and imaged using a confocal microscope. While dye functionalized HMSC were detected outside the cells and on the cell membrane after 15 and 60 minutes incubation time periods, successful internalization was observed after 24 hours when almost no particles could be detected extracellularly (Fig. 5). In addition, after 24 hours, no optically visible adverse effects on HeLa cells could be observed, which supported the results of the cell viability assay. Although the mechanism of the entry for HMSC-FAM conjugates has not been further investigated during this work, involvement of an endocytotic pathway is very likely to play a crucial role considering the submicrometer size of the particles. ${ }^{27}$

To demonstrate the versatility of HMSC, capsules were loaded with a hydrophilic and a hydrophobic model drug via diffusion through the mesoporous shell. While ciprofloxacin, a commonly used antibiotic, was used as hydrophilic substance, curcumin, a natural colorant that has shown very interesting antibiotic as well as anticancer activities, ${ }^{28}$ was employed as a hydrophobic model drug. Since ciprofloxacin exhibits higher solubility at lower $\mathrm{pH}$, drug loading was performed by mixing the particles with a known amount of the drug in $0.01 \mathrm{~N} \mathrm{HCl}$ (pH 1). In case of curcumin, loading was performed using ethanol as solvent. After 12 hours of loading, the particles were washed in order to remove any free molecules and the preheated $\left(37^{\circ} \mathrm{C}\right)$ release medium was added to the particles.

A pH-dependent sustained release of ciprofloxacin was observed in the medium as demonstrated in Fig. 6A. According to the solubility of the drug, highest release rates could be observed using $0.01 \mathrm{~N} \mathrm{HCl}$ followed by water ( $\mathrm{pH}$ 6.5) and PBS $(\mathrm{pH}$ 7.4). The burst release during the first hour resulted in the release of nearly $50 \%$ of the drug. Although the loaded HMSC were thoroughly washed before starting the release experiments, the surface adsorption as well as trapping inside the pores of the HMSC shell of small amount of ciprofloxacin molecules cannot be entirely ruled out. A slow release was observed during the following 60 hours, which implied the outward diffusion and release of molecules from the voids of HMSC. This value increased only marginally over the next 60 hours indicating that most of ciprofloxacin had been released after 120 hours release time. A similar influence of the release medium was observed for curcumin loaded particles (Fig. 6B). Due to the hydrophobic nature of the drug, release rates in ethanolic surroundings were nearly 10 times higher than those compared in water at $\mathrm{pH}$ 6.5. However, a burst release with quantitative drug release $(100 \%)$ could only be observed in ethanol. This is probably due to the hydrophobic nature of the drug that suppressed the chemisorption of the drug molecules

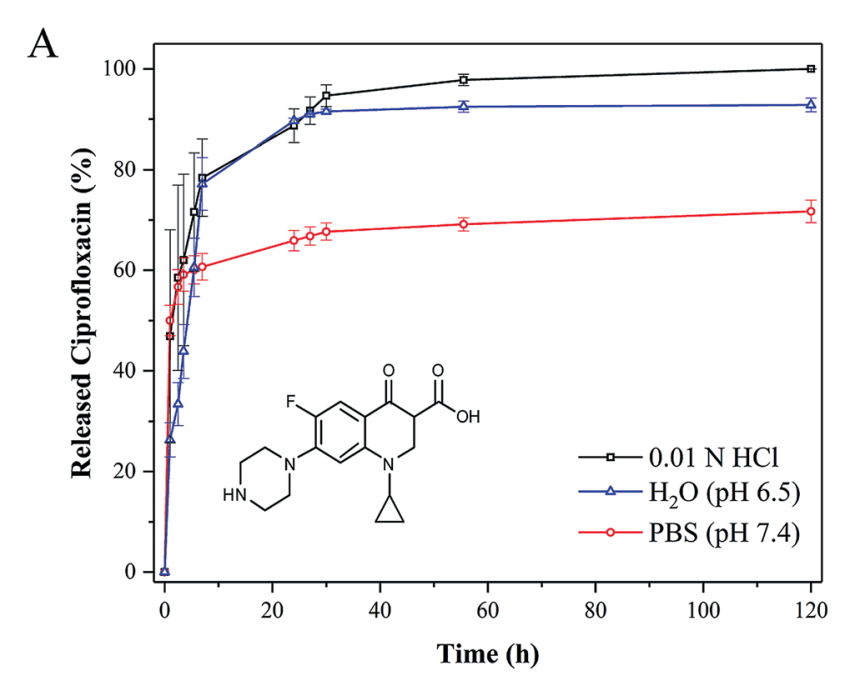

B

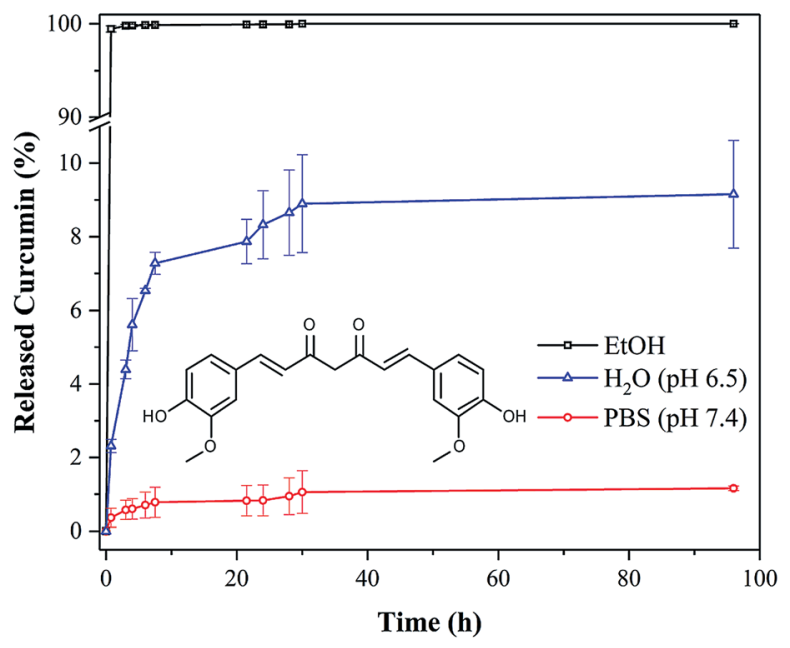

Fig. 6 Cumulative drug release of ciprofloxacin (A) and curcumin (B) from $\mathrm{HMSC}$ at $37^{\circ} \mathrm{C}$ in different release media. Error bars refer to three independent measurements. 
on the polar particle surface, generally occurring through hydrogen bondings. ${ }^{29}$ Even though the solubility of curcumin is very low in water, a slow release of the drug could be observed at $\mathrm{pH}$ 6.5. The released amounts after 7 hours (7\%), 24 hours (8\%) and 96 hours (9\%) suggested a sustained release. With both therapeutics, the lowest release could be observed when using PBS as release medium, although release rates were considerably higher in terms of ciprofloxacin due to the higher solubility. It is known that the high salt environment of PBS leads to a significant effect on the surface charge of HMSC, which decreases their colloidal stability. As a result, particles tend to sediment and agglomerate, eventually hampering the continuous release of the drug.

The disintegration of amorphous mesoporous silica nanoparticles in aqueous environment to silicic acid ${ }^{30}$ includes three main steps involving the adsorption of water to the siloxane framework, followed by the hydrolysis of siloxane to silanols and the nucleophilic attack of hydroxyl ions that leads to leaching of silicic acid. The reaction kinetics of this process is highly dependent on the surface area of particles and completion can take 24 hours to several weeks. In view of their application in human bodies, it is of great importance to know that the degradation products are nontoxic and can be excreted via the kidneys. ${ }^{31}$

To investigate the degradation of HMSC prepared in this work, particles were loaded with ciprofloxacin and release experiments in water ( $\mathrm{pH}$ 6.5) were performed at $37^{\circ} \mathrm{C}$. Typically, the release experiments were carried out for two weeks and the supernatant was removed every 12 hours and replenished with equivalent amounts of fresh water. The TEM images of hollow silica capsules taken before and after two weeks release of ciprofloxacin in water showed a clear reduction in particle shell thickness from 52 to $39 \mathrm{~nm}$ indicating the dissolution of particles over time (Fig. 7C). The slightly acidic release medium of water at pH 6.5 is expected to have a main influence on the dissolution kinetics as Lindén and co-workers could show that in alkaline conditions, due to the presence of nucleophilic hydroxyl ions, which can attack the $\mathrm{Si}-\mathrm{O}-\mathrm{Si}$ bonds, the dissolution of silica particles is accelerated..$^{32}$ Degradation of the particles usually starts by the dissolution of thin pore walls in the outer particle shell. This is in accordance to the microscopic images that besides a reduction in shell thickness revealed cracks on the particle surface (Fig. 7D).

In order to demonstrate that the loaded ciprofloxacin amounts are sufficient to inhibit bacterial growth, the antibacterial activity of ciprofloxacin loaded HMSC was evaluated using E. coli as model bacteria in an antibacterial kinetic growth assay. The growth inhibition of the bacteria was detected by measuring the optical density at $600 \mathrm{~nm}\left(\mathrm{OD}_{600}\right)$ of samples with and without (negative control) drug-loaded HMSC. Additionally, a positive control with $0.2 \mu \mathrm{g} \mathrm{ml} \mathrm{m}^{-1}$ pure ciprofloxacin was performed resulting in complete growth inhibition of $E$. coli (Fig. 8). A concentration dependent effect on the growth of $E$. coli could be detected in terms of ciprofloxacin loaded HMSC, which demonstrated a homogenous release of the drug in aqueous environment. A complete growth inhibition of bacteria could be detected at concentrations of $10 \mu \mathrm{g} \mathrm{ml}{ }^{-1}$, while no effect could be observed when using the same amount of nonloaded HMSC. This demonstrates that the antibacterial effect is evidently related to the continuous release of ciprofloxacin from the HMSC. Moreover, a slight inhibitory effect can also be seen at very low concentrations of $1.07 \mu \mathrm{g} \mathrm{ml} \mathrm{m}^{-1}$. By calculating the released amount of ciprofloxacin out of $1.07 \mu \mathrm{g} \mathrm{ml}^{-1}$ after 18 hours, a value of $0.022 \mu \mathrm{g} \mathrm{ml} \mathrm{m}^{-1}$ of released drug can be

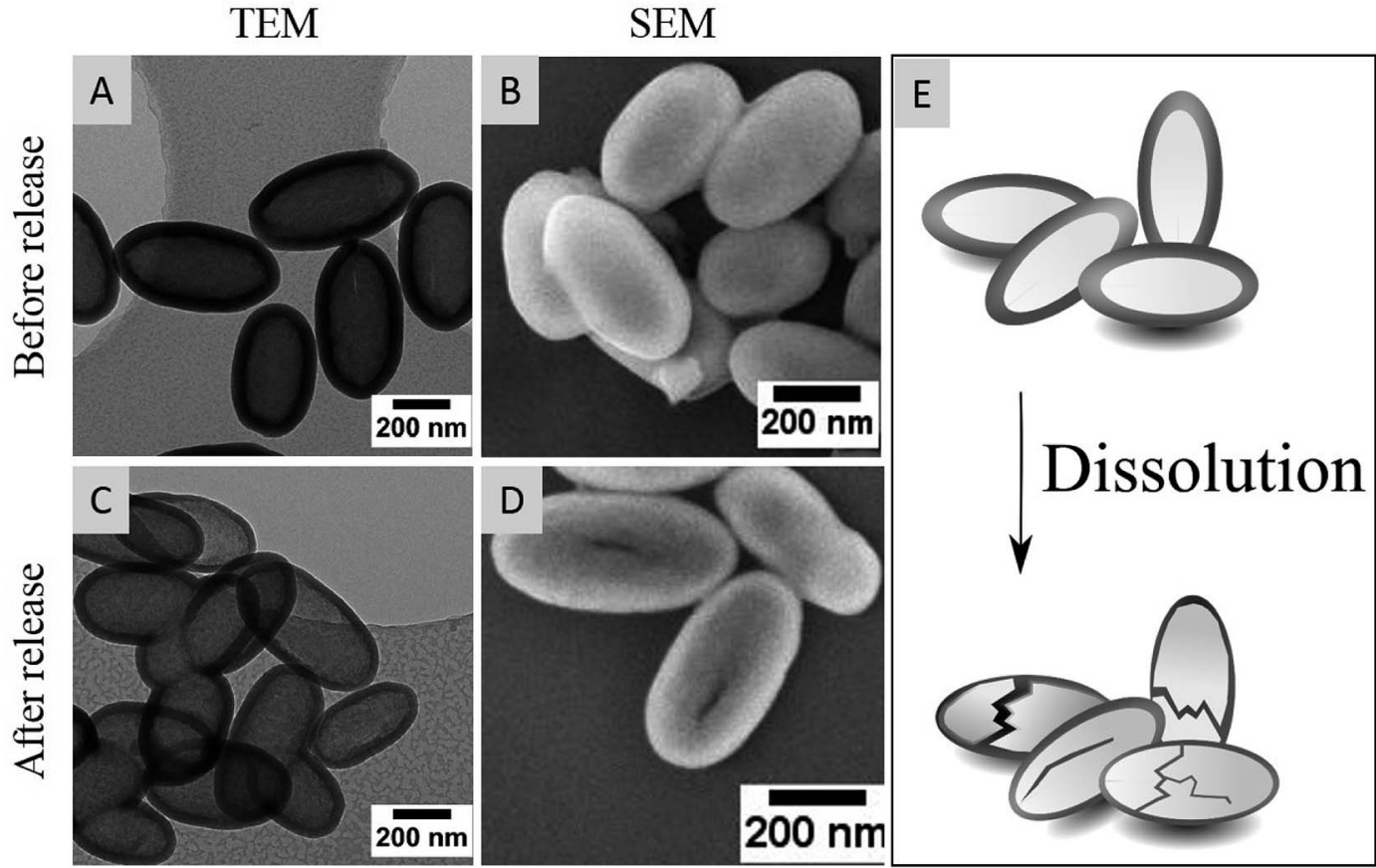

Fig. 7 TEM ( $A$ and C) and SEM (B and D) images before and after the release of ciprofloxacin out of hollow silica capsules at $37^{\circ} \mathrm{C}$ for two weeks. (E) Schematic dissolution of HMSC. 


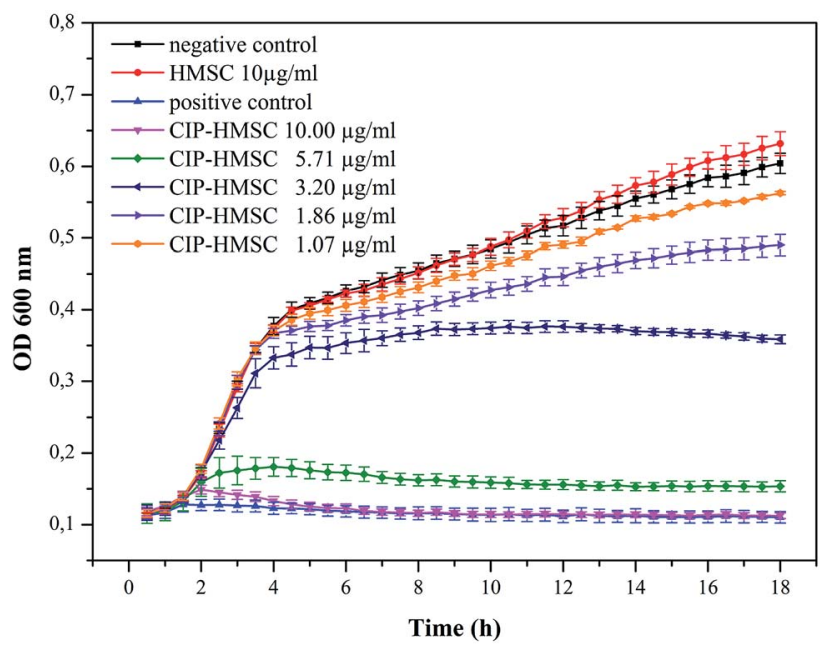

Fig. 8 Microbial growth kinetics of $E$. coli bacteria in the presence of ciprofloxacin loaded HMSC (CIP-HMSC). As reference, HMSC without the drug were tested (HMSC $10 \mu \mathrm{g} \mathrm{ml}^{-1}$ ), as well as a negative control (no addition of drugs/particles) and a positive control (pure ciprofloxacin $0.2 \mu \mathrm{g} \mathrm{ml}^{-1}$ ).

obtained. This is very close to literature known minimal inhibition concentrations (MIC) of ciprofloxacin toward E. coli of $0.015 \mu \mathrm{g} \mathrm{ml}^{-1} .{ }^{33}$ Additionally, the amount of drug released from $10 \mu \mathrm{g} \mathrm{ml}{ }^{-1}$ ciprofloxacin loaded HMSC corresponds to $0.21 \mu \mathrm{g}$ $\mathrm{ml}^{-1}$ ciprofloxacin that was used as positive control and demonstrated in both cases a complete growth inhibition of the bacteria.

The incorporation of drugs into hollow capsules offers several advantages compared to the conventional administration of the free drug. For instance, (i) the drug is protected from a potential degradation inside the cells, (ii) a sustained release over long time periods is possible and release kinetics could be additionally controlled through the attachment of stimuliresponsive molecules that open and close the pores, (iii) drug delivery in nanocontainers allows a lower systemic toxicity as in total less drug is needed due to localized release occurring only around the capsules, (iv) drug vectorization can be specifically enhanced by attaching targeting ligands on the particle surface to direct the drug-loaded particles to the point of interest and (v) the chemically active anchor points on the surface of capsules can be used for immobilization of other functional (bio)molecules such as imaging moieties to obtain dual-mode nano-bio conjugates.

\section{Conclusion}

Novel drug delivery vehicles with high compatibility under physiological conditions and biodegradability as well as large protected voids for the transport of drugs are of major interest for future therapeutics. Compared to most of the published data that focus on the formation of spherical mesoporous silica particles, in this work, a simple and reproducible synthesis of ellipsoid-shaped HMSC was demonstrated following a hard template assisted route. Porous silica capsules exhibited a high colloidal stability and were successfully loaded with both, hydrophilic (ciprofloxacin) as well as hydrophobic (curcumin) drugs. A sustained release was demonstrated for both types of drug loaded particles in water $(\mathrm{pH} 6.5)$ at $37{ }^{\circ} \mathrm{C}$. The small amounts of ciprofloxacin released were found to be effective in inhibiting the growth of $E$. coli bacteria. Moreover, a slow degradation of ciprofloxacin loaded HMSC in water was observed which is essential for a biocompatible and degradable drug transporter.

\section{Conflicts of interest}

The authors declare no conflicts of interest.

\section{Acknowledgements}

The authors gratefully acknowledge the financial support provided by the University of Cologne. Special thanks are given to Dr Stefan Roitsch and Dr Lena Grassberger for TEM and SEM measurements, respectively. Furthermore, the help of Dr Christian Jüngst during confocal microscopy is greatly acknowledged.

\section{References}

1 P. Yang, S. Gai and J. Lin, Chem. Soc. Rev., 2012, 41, 36793698.

2 F. Tang, L. Li and D. Chen, Adv. Mater., 2012, 24, 1504-1534.

3 Q. He and J. Shi, J. Mater. Chem., 2011, 21, 5845-5855.

4 M. Vallet-Regí, F. Balas and D. Arcos, Angew. Chem., Int. Ed., 2007, 46, 7548-7558.

5 Z. Li, J. C. Barnes, A. Bosoy, J. F. Stoddart and J. I. Zink, Chem. Soc. Rev., 2012, 41, 2590-2605.

6 F. Caruso, R. A. Caruso and H. Möhwald, Science, 1998, 282, 1111-1114.

7 X. W. Lou, L. A. Archer and Z. Yang, Adv. Mater., 2008, 20, 3987-4019.

8 J. Hu, M. Chen, X. Fang and L. Wu, Chem. Soc. Rev., 2011, 40, 5472-5491.

9 Y. Zhu, J. Shi, W. Shen, X. Dong, J. Feng, M. Ruan and Y. Li, Angew. Chem., Int. Ed., 2005, 117, 5213-5217.

10 J. Pang, X. Li, G. Zhou, B. Sun and Y. Wei, $R S C$ Adv., 2015, 5, 6599-6606.

11 Y. Gao, Y. Chen, X. Ji, X. He, Q. Yin, Z. Zhang, J. Shi and Y. Li, ACS Nano, 2011, 5, 9788-9798.

12 X. Huang, X. Teng, D. Chen, F. Tang and J. He, Biomaterials, 2010, 31, 438-448.

13 Y. Chen, H. Chen, D. Zeng, Y. Tian, F. Chen, J. Feng and J. Shi, ACS Nano, 2010, 4, 6001-6013.

14 B. Lv, Y. Xu, D. Wua, Y. Sun, D. Wu and Y. Sun, CrystEngComm, 2011, 13, 7293-7298.

15 L. Wortmann, S. Ilyas, D. Niznansky, M. Valldor, K. Arroub, N. Berger, K. Rahme, J. Holmes and S. Mathur, ACS Appl. Mater. Interfaces, 2014, 6, 16631-16642.

16 Y. S. Han, G. Y. Jeong, S. Y. Lee, K. H. Moon and H. K. Kim, Mater. Lett., 2009, 63, 1278-1280. 
17 B. D. Zlatopolskiy, P. Krapf, R. Richarz, H. Frauendorf, F. M. Mottaghy and B. Neumaier, Chem.-Eur. J., 2014, 20, 4697-4703.

18 S. Ilyas, M. Ilyas, R. a L. Van Der Hoorn and S. Mathur, ACS Nano, 2013, 7, 9655-9663.

19 Y. Tian, J. Qi, W. Zhang, Q. Cai and X. Jiang, ACS Appl. Mater. Interfaces, 2014, 6, 12038-12045.

20 B. X. Hu and J. C. Yu, Adv. Funct. Mater., 2008, 18, 880-887. 21 S. Bruni, F. Cariati, M. Casu, A. Lai, A. Musinu, G. Piccaluga and S. Solinas, Nanostructured Mater., 1999, 11, 573-586.

22 X. Zhang, Y. Niu, Y. Li, Y. Li and J. Zhao, J. Solid State Chem., 2014, 211, 69-74.

23 S. C. Feifel and F. Lisdat, J. Nanobiotechnol., 2011, 9, 1-12.

24 N. E. A. El-Gamel, L. Wortmann, K. Arroub and S. Mathur, Chem. Commun., 2011, 47, 10076-10078.

25 S. Brunauer, L. S. Deming, W. E. Deming and E. Teller, J. Am. Chem. Soc., 1940, 62, 1723-1732.
26 M. Thommes, K. Kaneko, A. V. Neimark, J. P. Olivier, F. Rodriguez-Reinoso, J. Rouquerol and K. S. W. Sing, Pure Appl. Chem., 2015, 87, 1051-1069.

27 G. Sahay, D. Y. Alakhova and A. V. Kabanov, J. Controlled Release, 2010, 145, 182-195.

28 B. B. Aggarwal, C. Sundaram, N. Malani and H. Ichikawa, in The Molecular Targets and Therapeutic Uses of Curcumin in Health and Disease, ed. B. B. Aggarwal, Y.-J. Surh and S. Shishodia, Springer US, Boston, MA, 2007, pp. 1-75.

29 J. M. Rosenholm and M. Lindén, J. Controlled Release, 2008, 128, 157-164.

30 J. G. Croissant, Y. Fatieiev and N. M. Khashab, Adv. Mater., 2017, 29, 1604634.

31 D. M. Reffitt, R. Jugdaohsingh, R. P. H. Thompson and J. J. Powell, J. Biol. Inorg. Chem., 1999, 76, 141-147.

32 K. Braun, A. Pochert, M. Beck, R. Fiedler, J. Gruber and M. Lindén, J. Sol-Gel Sci. Technol., 2016, 79, 319-327.

33 J. M. Andrews, J. Antimicrob. Chemother., 2001, 48, 5-16. 